\title{
Ergoterapi Lisans Öğrencilerinde Yaşlılara Yönelik Tutum ve Özgeciliğin İncelenmesi
}

Examination of Attitudes and Altruism Towards the Elderly in Occupational Therapy Undergraduate Students

\section{Özgü INAL ${ }^{1}$, Hülya YÜCEL ${ }^{2}$}

1 Dr. Öğr. Üyesi, Sağlık Bilimleri Üniversitesi Gülhane Sağlık Bilimleri Fakültesi Ergoterapi Bölümü, Ankara, Türkiye

2 Doç. Dr., Sağlık Bilimleri Üniversitesi Hamidiye Sağlık Bilimleri Fakültesi Ergoterapi Bölümü, İstanbul, Türkiye

\section{öz}

\begin{abstract}
Amaç: Bu çalışmanın amacı; ergoterapi lisans öğrencilerinde yaşılıara yönelik tutum ve özgeciliğin incelenmesidir. Gereç ve Yöntem: Bu çalışma 175 Ergoterapi lisans öğrencisi ile gerçekleştirildi. Çalışma çevrimiçi olarak gerçekleştirildi, katııımcılara araştırmacılar tarafından hazırlanan bilgi formu ile Yaşlılara Yönelik Tutum Ölçeği (YYTÖ) ve Özgecilik Ölçeği (ÖÖ) gönderildi. Sonuçlar: Çalışmada katılımcıların yaşlı bireyler ile ilgili nitel sorulara verdikleri yanıtlar ön-test ve son-test şeklinde incelendi ve genel olarak olumsuz düşüncelerinin azaldığı ve olumlu düşüncelerinin arttığı belirlendi. Mezuniyet sonrası yaşlı bireylerle çalışmayı düşünen ergoterapi lisans öğrenci sayısında da öğrenim yıllarına göre artış saptandı (\%43.43). YYTÖ ve ÖÖ açısından ise ön-test ve son-test değerlendirmeleri arasında istatistiksel olarak anlamlı bir fark olduğu belirlendi $(p<0.05)$. Elde edilen verilere göre öğrencilerin yaşı bireylerle ilgili olumsuz tutumunda azalma olurken, olumlu tutumlarında ise artı̧ saptandı. Ayrıca öğrencilerin özgecilik düzeylerinde de artış olduğu belirlendi. Tartışma: Çalışmadan elde edilen sonuçlar çevrimiçi ergoterapi lisans eğitiminin olumlu etkilerine dikkat çekmektedir. Yaşlanan nüfus artışı göz önüne alındığında; ergoterapi lisans müfredatı öğrenciler için yaşlanma ve yaşıılıkla ilgili daha fazla içeriği kapsayabilir.
\end{abstract}

Anahtar Kelimeler: Ergoterapi; Öğrenciler; Eğitim; Yaşıl; Özgecilik.

\section{ABSTRACT}

Purpose: The aim of this study is to examine altruism and attitude towards the elderly in occupational therapy undergraduate students. Material and Methods: This study was carried out with 175 occupational therapy undergraduate students. The study was conducted online and the participants were sent the Attitude Towards the Elderly Scale (ATES) and the Altruism Scale (AS) with the information form prepared by the researchers. Results: In the study, participants' responses to qualitative questions about older individuals were examined as pre-test and post-test, and it was determined that their negative thoughts in general decreased, and their positive thoughts increased. There was also an increase in the number of occupational therapy undergraduate students considering working with older individuals after graduation $(43.43 \%)$. In terms of the ATES and AS, there was a stastisitically significant difference between the pre-test and the post-test evaluations $(p<0.05)$. It was also found that there was an increase in the level of altruism of students. Discussion: The results of the study draw attention to the positive effects of online occupational therapy undergraduate education. Considering the ageing population growth, the occupational therapy undergraduate curriculum may cover more content related to aging and old age for students.

Keywords: Occupational therapy; Students; Education; Elderly; Altruism 
Ergoterapi eğitiminin amacı, uygulama için gereken mesleki yeterliliklere sahip öğrenciler yetiştirmektir (WFOT, 2021). Ergoterapi, her bir danışanın anlamlı yaşam aktivitelerine katılımını, devam etmesini ve sağlığı sürdürme becerisini sağlamayı amaçlayan kişi merkezli uygulamaya dayanır (Whalley Hammell, 2015; AOTA, 2008).

Ülkemizdeki yaşlı birey sayısı tüm dünyada olduğu gibi giderek artmaktadır. Dünya Sağlık Örgütü'ne göre bir ülkenin nüfusunun \%7'si ve fazlası yaşı ise o toplum yaşlı kabul edilmektedir. Türkiye İstatistik Kurumu 2018 verilerine göre (TÜIK, 2018) 65 yaş ve üzeri nüfus, 2014 yılında $\% 8$ iken, bu oran 2018 yılında \%8.8'e yükselmiştir. 2023 yılında ise bu oranın \%10.2 olacağı öngörülmektedir. Ülkemizde ve dünyada yaşlı nüfusun hızla artması nedeni ile, yaşlı bireylerin yaşadığı sorunlar daha önemli hale gelmiştir. Bu sorunların en önemlilerinden biri yaşlı bireyleri yük olarak görme gibi olumsuz tutumlardır (WHO,2016-2020).

Yaşılıardaki demografik değişimler ergoterapistler de dâhil olmak üzere sağlık hizmeti sağlayıcılarına olan talebi arttırmıştır (Maiden, Horowitz ve Howe, 2010; Powell, Kanny ve Ciol, 2008). Yaşlanma, hastalık veya yeti yitimi ile eşanlamlı değildir, ancak ileri yaş kırılganlık, kronik hastalık, yeti yitimi riskini artırır ve kronik hastalıkların yönetimi, rehabilitasyon, ev sağlığı, sosyal hizmetleri ve uzun vadeli sağlık bakımı hizmetlerine olan talebi artırır (Administration on Aging, 2003; New York State Office for the Aging, 2011-2015).

Yaşlanma, yaşlanma kaygısı ve yaşlı yetişkinlere yönelik olumsuz tutumlar, bireylerin kariyer seçimleri üzerinde etkilidir (Brown, Kother ve Wielandt, 2011; Eshbaugh, Gross ve Satrom, 2010; Klein ve Liu, 2010). Ergoterapistler hem mesleki uygulamalarında hem de mezuniyet sonrası yaşlı bireylerle yaygın olarak çalışmaktadırlar. Literatürde ergoterapi mesleğinin seçiminde bireylerin yardımsever ve özgeci yapılarının önemine dikkat çekilmiştir (Rozier, Gilkeson ve Hamilton, 1992).

Özgecilik ilk kez 19. yüzyılın sonlarında başkaları için yaşama eğilimi ve arzusu olarak tanımlanmıştır ve başka bireylere yardım etmenin sağladığı memnuniyet duygusuna ek olarak karşılık beklemeden gönüllü olarak iyilik yapmak olarak ifade edilmektedir (Taylor, Peplau ve Sears, 2010). Ayrıca özgecilik; başka bireylerin sorunları karşısında hissedilen empati duygusunun davranışsal yönüdür (Eisenberg, Fabes ve
Spinrad, 2006).

Sağlık çalışanlarının yaşılıara yönelik tutumları yaşılıara verilen sağlık hizmetinin temelinde yer alır. Yaşııık ve ergoterapiyi ele alan sınırlı çalışmalar olsa $\mathrm{da}$, ergoterapistler arasında yaşlanmaya ilişkin daha olumlu tutumlar olduğuna dair bazı kanıtlar vardır (Klein ve Liu, 2010; Horowitz, Savino ve Krauss, 1999). Bununla birlikte, ergoterapi lisans eğitiminin yaşlılara yönelik tutum ve özgeceliği nasıl etkilediğine dair bir çalışmaya rastlanmamıştır.

Ergoterapi lisans eğitiminde yaşlı bireylerle ilgili eğitimlerin alınması, gelecekte terapistlerin yaşlı bireylerin, ailelelerin ve yaşlanan toplumun intiyaçlarını ele almasını sağlamak açısından önemlidir (Horowitz, Tagliarino ve Look, 2014). Sağlık personelinin yaşlanmaya ve yaşlılara yönelik inançları ve olumsuz tutumları, yaşlılara verilen hizmetlerin verimliliğinde ve kalitesinde düşüşe neden olabilir (Yazıcı, Kalaycı, Kaya ve Tekin, 2015).

$\mathrm{Bu}$ çalışmanın amacı; ergoterapi lisans öğrencilerinde yaşılıara yönelik tutum ve özgeciliğin incelenmesidir. Sonuçların ergoterapi lisans programlarının içeriği açısından ve genel literatüre katkı sağlaması açısından önemli olduğu düşünülmektedir.

\section{GEREÇ VE YÖNTEM}

Sağlık Bilimleri Üniversitesi Hamidiye Sağlık Bilimleri Fakültesi Ergoterapi Bölümü'nde 2020-2021 güz döneminde yürütülen bu çalışma için gerekli etik kurul izni alınmıştır (Trakya Üniversitesi Sosyal ve Beşeri Bilimler Araştırmaları Etik Kurulu; karar no: 2020.07.01). Ergoterapi bölümünde eğitim gören 332 lisans öğrencisi mevcuttu. Öğrencilere Google formda hazırlanan bilgi formu (yaş, cinsiyet, sınıf, yaşı kelimesinin anlamı, yaşlanmak konusundaki düşünceler, yaşlı bireylerin üretkenlik aktivitelerine devam edip edemeyeceği ve mezuniyet sonrası yaşlı bireylerle çalışmak isteyip istemedikleri ile ilgili soruların olduğu), Yaşılıara Yönelik Tutum Ölçeği ve Özgecilik Ölçeği çevrimiçi olarak gönderilmiştir. Ölçeklerin başında araştırma ile ilgili açıklayıcı bir bilgi yazısı yazıımıştır. Çalışmaya katılmak isteyen bireyler bu yazının altında bulunan "araştırmaya katılmayı onaylıyorum" ibaresini işaretledikten sonra anketleri cevaplamışlardır ve çalışmaya katılmayı onaylayan 175 öğrenci ile çalışma gerçekleştirilmiştir. Ölçekler aynı eğitim yılının güz döneminin başında (ön test) ve dönem sonunda (son test) olmak üzere iki kere uygulanmıştır. Dönem sonunda bireylerin ölçeklere verdikleri cevaplar karşılaştıııımıştır.

Veri Toplama Araçları

Yaşılıara Yönelik Tutum Ölçeği (YYTÖ): Kogan (1961) tarafından bireylerin yaşılıara yönelik tutumlarını 
değerlendirmek amacı ile geliştirilmiştir. Türkçe versiyonunu Duyan ve Gelbal'ın (2013) yaptığı ölçekte 17 olumsuz ve 17 olumlu olmak üzere, 6'li Likert tipinde 34 madde bulunmaktadır. Ölçekte olumlu ve olumsuz maddelere verilen yanıtlar ayrı ayrı toplanmaktadır. Yaşlılara yönelik olumlu tutumlar bölümünden alınan yüksek ve yaşlılara yönelik olumsuz tutumlar bölümünden alınan düşük puanlar yaşlı bireylere yönelik olumlu tutuma sahip olunduğunu göstermektedir.

Özgecilik Ölçeği (ÖÖ): Ölçek, London ve Bower (1968) tarafından bireylerin özgecilik düzeylerini ölçmek için geliştirilmiş ve Akbaba (1994) tarafından Türkçe'ye uyarlaması yapılmıştır. Ölçek toplam 20 madde ve 4 alt boyuttan oluşan (aile boyutu, sosyal boyut, yardımseverlik boyutu ve sorumluluk boyutu) 5'li Likert tipi ölçektir. Ölçekten alınan puanın yüksekliği; özgecilik düzeyinin yüksek olduğunu gösterir.

\section{Istatistiksel Analiz}

Katılımcılardan elde edilen veriler Excel programına aktarıldı. Daha sonra veriler IBM SPSS Statistics 21 (Statistical Package for the Social Science) programına kodlanarak, gerekli analizler yapıldı. Katılımcıların tanımlayıcı özellikleri ile ilgili analizler; frekans, yüzde dağılımı, ortalama \pm standart sapma olarak verildi. Nitel sorulara verilen cevaplar için betimsel içerik analizi kullanıldı. Verilerin normal dağılımı Kolmogorov-Smirnov testi ile incelendi. Ön test ve son test değerlerinin karşılaştırılmasında ise Paired Sample t-Test kullanıldı. Normal dağılım gösteren grupların karşılaştırmalarında One-way ANOVA test ve ikili karşılaştırmalarda Bonferroni Test kullanıldı. Anlamlılık değeri $p<0.05$ olarak kabul edildi.

\section{SONUÇLAR}

Çalışma 148 kadın ve 27 erkek, yaş ortalaması

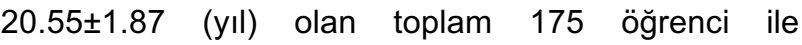
tamamlandı. Çalışmaya 1. sınıftan 45 (\%25.71), 2. sınıftan 43 (\%24.57), 3. sınıftan $44(\% 25.14)$ ve 4. sınıftan 43 (\%24.57) öğrenci katıldı.

Çalışmada katılımcıların yaşlı bireyler ile ilgili nitel sorulara verdikleri yanıtlar ön-test ve son-test olarak incelendiğinde; genel olarak olumsuz düşüncelerinin azaldığı (örn.hasta/bunak) ve olumlu düşüncelerinin arttığı belirlendi (örn. deneyimli/tecrübeli). Ayrıca mezuniyet sonrası yaşlı bireylerle çalışmayı düşünen ergoterapi lisans öğrenci sayısında da öğrenim yıllarına göre artış saptandı (\%43.43) (Tablo 1).

Tablo 1. Katılımcıların yaşlı bireylerle ilgili sorulara verdiği cevaplar.

\begin{tabular}{|c|c|c|c|c|}
\hline & \multicolumn{2}{|l|}{ Ön test } & \multicolumn{2}{|l|}{ Son test } \\
\hline & & n (\%) & & n (\%) \\
\hline \multirow[t]{19}{*}{ Yaşlı kelimesinin anlamı } & yaşlanmış/yaşı ilerlemiş/yaş almış & $44(25.14)$ & yaşlanmış/yaşı ilerlemiş/yaş almış & $47(26.86)$ \\
\hline & deneyimli/tecrübeli & $24(13.71)$ & deneyimli/tecrübeli & $30(17.14)$ \\
\hline & kısıtlanmış/kısıtlı/zorluk & $20(11.43)$ & bilge/çınar/değer & $17(9.71)$ \\
\hline & hasta/bunak & $16(9.14)$ & yaşanmışlık & $15(8.57)$ \\
\hline & hassas/kırılgan & $10(5.71)$ & kısıtlanmış/kısıtlı/zorluk & $13(7.43)$ \\
\hline & yorgun/yavaş & $10(5.71)$ & hasta/bunak & $11(6.28)$ \\
\hline & bebek/çocuk & $8(4.57)$ & değerli & $10(5.71)$ \\
\hline & verimsiz/yetersiz & $8(4.57)$ & hassas/kırılgan & $8(4.57)$ \\
\hline & bilge/çınar/değer & $6(3.43)$ & yorgun/yavaş & $6(3.43)$ \\
\hline & değerli & $5(2.86)$ & aile & $4(2.28)$ \\
\hline & aile & $5(2.86)$ & verimsiz/yetersiz & $3(1.71)$ \\
\hline & huysuz & $4(2.28)$ & ölüm & $2(1.14)$ \\
\hline & yaşanmışlık & $3(1.71)$ & bağımlı/bakıma muhtaç & $2(1.14)$ \\
\hline & bağımlı/bakıma muhtaç & $3(1.71)$ & bebek/çocuk & $2(1.14)$ \\
\hline & dede/sevimli & $2(1.14)$ & dede/sevimli & $1(0.57)$ \\
\hline & saygı & $2(1.14)$ & yalnız & $1(0.57)$ \\
\hline & ölüm & $2(1.14)$ & emekli & $1(0.57)$ \\
\hline & yalnız & $2(1.14)$ & saygı & $1(0.57)$ \\
\hline & emekli & $1(0.57)$ & huysuz & $1(0.57)$ \\
\hline Yaşlanmak istiyor musunuz? & evet & $53(30.28)$ & evet & $44(25.14)$ \\
\hline $\begin{array}{l}\text { Yaşlı bireylerde üretkenlik } \\
\text { aktiviteleri devam eder mi? }\end{array}$ & evet & $138(78.86)$ & evet & $169(96.57)$ \\
\hline \multirow{3}{*}{$\begin{array}{l}\text { Mezuniyet sonrası yaşlı } \\
\text { bireylerle çalışmak istermisiniz? }\end{array}$} & evet & $57(32.57)$ & evet & $76(43.43)$ \\
\hline & hayır & $37(21.14)$ & hayır & $23(13.14)$ \\
\hline & kararsızım & $81(46.28)$ & kararsızım & $76(43.43)$ \\
\hline
\end{tabular}


Çalışmada katıımcıların yaşılıara yönelik tutumları ve özgecilik düzeyleri sınıf düzeylerine göre incelenmiştir ve sınıflar arasında ölçek son test sonuçları açısından Özgecilik Ölçeği aile $(p=0.04)$ ve sorumluluk alt boyutunda anlamlı bir fark bulunmuştur $(p<0.01)$ (Tablo 2). Aile boyutundaki fark 1. sinıf ve 2. sinıf arasında iken $(p=0.04)$, sorumluluk alt boyutundaki fark 1 . sınıf ile 2,3 ve 4 . sınıflar arasındadır $(p<0.01)$.
YTÖ ve ÖÖ açısından ise ön test ve son test değerlendirmeleri arasında istatistiksel olarak anlamlı fark olduğu belirlendi $(p<0.05)$. Elde edilen verilere göre öğrencilerin yaşlı bireylerle ilgili olumsuz tutumunda azalma olurken, olumlu tutumlarında ise artış saptandı. Ayrıca öğrencilerin özgecilik düzeylerinde de artış olduğu belirlendi (Tablo 3).

Tablo 2. Sınıf seviyesine göre öğrencilerin yaşlılara yönelik tutumları ve özgeciliklerinin sonuçları

\begin{tabular}{|c|c|c|c|c|c|c|c|c|c|}
\hline & \multicolumn{2}{|c|}{ 1.Sınıf $(n=45)$} & \multicolumn{2}{|c|}{ 2.Sınıf $(n=43)$} & \multicolumn{2}{|c|}{ 3.Sınıf $(n=44)$} & \multicolumn{2}{|c|}{ 4.Sınıf $(n=43)$} & \\
\hline YYTÖ & \multicolumn{2}{|c|}{ Mean $\pm S S$} & \multicolumn{2}{|c|}{ Mean $\pm S S$} & \multicolumn{2}{|c|}{ Mean $\pm S S$} & \multicolumn{2}{|c|}{ Mean $\pm S S$} & $p^{*}$ \\
\hline Olumsuz Tutum & $99.09 \pm 6.19$ & $97.45 \pm 5.37$ & $99.00 \pm 6.22$ & $95.46 \pm 9.31$ & $100.75 \pm 5.7$ & $96.41 \pm 7.93$ & $100.38 \pm 5.5$ & $93.43 \pm 8.42$ & 0.10 \\
\hline Olumlu Tutum & $76.75 \pm 9.06$ & $81.45 \pm 11.8$ & $76.23 \pm 12.5$ & $84.69 \pm 7.65$ & $80.29 \pm 10.5$ & $83.6 \pm 11.72$ & $80.46 \pm 10.3$ & $84.69 \pm 8.71$ & 0.36 \\
\hline ÖÖ & \multicolumn{2}{|c|}{ Mean $\pm S S$} & \multicolumn{2}{|c|}{ Mean $\pm S S$} & \multicolumn{2}{|c|}{ Mean $\pm S S$} & \multicolumn{2}{|c|}{ Mean $\pm S S$} & $p^{*}$ \\
\hline Aile & $19.21 \pm 2.69$ & $19.51 \pm 2.48$ & $19.05 \pm 2.67$ & $20.90 \pm 1.87$ & $19.77 \pm 2.65$ & $20.57 \pm 2.85$ & $18.59 \pm 2.21$ & $20.18 \pm 2.33$ & 0.04 \\
\hline Sosyal & $15.87 \pm 4.43$ & $15.58 \pm 3.33$ & $15.13 \pm 3.10$ & $16.82 \pm 4.07$ & $16.02 \pm 3.93$ & $17.39 \pm 4.72$ & $14.79 \pm 3.84$ & $16.38 \pm 4.36$ & 0.18 \\
\hline Yardımseverlik & $16.96 \pm 3.59$ & $18.26 \pm 3.11$ & $16.31 \pm 2.86$ & $18.87 \pm 2.53$ & $17.20 \pm 3.35$ & $18.00 \pm 3.56$ & $16.28 \pm 3.42$ & $18.20 \pm 3.34$ & 0.64 \\
\hline Sorumluluk & $18.23 \pm 2.84$ & $21.49 \pm 2.20$ & $17.43 \pm 2.23$ & $18.85 \pm 2.56$ & $18.70 \pm 2.33$ & $18.68 \pm 1.96$ & $17.51 \pm 1.97$ & $18.08 \pm 2.57$ & $<0.01$ \\
\hline Toplam & $70.26 \pm 10.7$ & $74.85 \pm 6.62$ & $67.92 \pm 7.13$ & $75.43 \pm 7.98$ & $71.70 \pm 8.59$ & $74.64 \pm 8.50$ & $67.18 \pm 6.70$ & $72.85 \pm 9.39$ & 0.52 \\
\hline
\end{tabular}

YYTÖ: Yaşlılara Yönelik Tutum Ölçeği, ÖÖ: Özgecilik Ölçeği Paired Samples T-Test , *One-Way Anova Test, $p<0.05$

Tablo 3. Öğrencilerin Yaşlılara Yönelik Tutumları ve Özgeciliklerinin Ön-test ve Son-test Sonuçları

\begin{tabular}{|c|c|c|c|c|c|c|c|}
\hline & & \multicolumn{2}{|c|}{ Ön test } & \multicolumn{3}{|c|}{ Son test } & \multirow[b]{2}{*}{$p$} \\
\hline & & Min-maks & Mean $\pm S S$ & Min-maks & Mean $\pm S S$ & $T$ & \\
\hline \multirow[t]{2}{*}{ YYTÖ } & Olumsuz Tutum & $86-119$ & $99.78 \pm 5.93$ & $69-119$ & $95.85 \pm 7.80$ & 5.46 & $<0.01$ \\
\hline & Olumlu Tutum & $46-104$ & $78.35 \pm 10.80$ & $54-117$ & $83.33 \pm 10.16$ & -4.32 & $<0.01$ \\
\hline \multirow[t]{5}{*}{ ÖÖ } & Aile & $13-24$ & $19.18 \pm 2.59$ & $9-25$ & $20.23 \pm 2.46$ & -4.03 & $<0.01$ \\
\hline & Sosyal & $8-25$ & $15.50 \pm 3.91$ & $5-25$ & $16.49 \pm 4.13$ & -2.18 & 0.30 \\
\hline & Yardımseverlik & $5-25$ & $16.72 \pm 3.34$ & $7-24$ & $18.32 \pm 3.15$ & -4.45 & $<0.01$ \\
\hline & Sorumluluk & $11-25$ & $18.01 \pm 2.44$ & $13-25$ & $19.43 \pm 2.66$ & -5.59 & $<0.01$ \\
\hline & Toplam & $47-96$ & $69.42 \pm 8.72$ & $43-94$ & $74.48 \pm 8.06$ & -5.48 & $<0.01$ \\
\hline
\end{tabular}

YYTÖ: Yaşlılara Yönelik Tutum Ölçeği, ÖÖ: Özgecilik Ölçeği Paired Samples T-Test, $p<0.05$ 


\section{TARTIŞMA}

$\mathrm{Bu}$ çalışmanın amacı; ergoterapi lisans öğrencilerinde yaşlılara yönelik tutum ve özgeciliğin incelenmesidir. Çalışma sonucunda ergoterapi lisans öğrencilerinde ergoterapi eğitimi ile birlikte "yaşlı" kavramına yönelik olumlu düşüncelerin arttığı, mezuniyet sonrası yaşlı bireylerle daha çok öğrencinin çalışmak istediği belirlenmiştir. Öğrencilerin yaşlılara yönelik olumsuz tutumlarının azaldığı ve olumlu tutumlarının artığı saptanmıştır. Ayrıca özgecilik düzeylerinde de artış olduğu belirlenmiştir.

Gerontoloji biliminde yaşlı bireylerle çalışmak genellikle "istenmeyen bir durum" olarak algılanır ve çeşitli sağlık profesyonellerinin yaşlı yetişkinlerle çalışmayı seçmemelerinin nedenleri değişkenlik gösterir (Brown, Kother ve Wielandt, 2011; Eshbaugh, Gross ve Satrom, 2010). Farklı disiplinlerde yaşlı bireylerle çalışma konusunda mesleki ilgiyi/istekli olmayı teşvik eden faktörler arasında yaşlanmaya ilişkin düşük seviyelerde kaygı, yaşlı yetişkinlerle olumlu temas ve özellikle toplumda yaşayan yaşlı yetişkinler olmak üzere yaşlı yetişkinlerle çalışma deneyimi yer almaktadır (Eshbaugh, Gross ve Satrom, 2010; Bousfield ve Hutchison, 2010). Ergoterapide bu nedenler arasında sınırlı gerontoloji eğitimi, uygulayıcı rol modellerin eksikliği, sağlıklı yaşlı yetişkinlerle sınırlı deneyim, yaşlılarla çalışmaya saygı eksikliği, gerontoloji uygulamasına ilişkin olumsuz algılar ve kariyer gelişimini sınırlayan mesleki endişeler yer almaktadır (Klein ve Liu, 2010; Horowitz ve Vanner, 2010).

Sağlıkla ilgili bölümlerde öğrenim gören öğrencilerle yapılan çalışmalar incelendiğinde; yaşlı bireylere karşı olumlu tutum tespit eden çalışmaların fazla olduğu görülmüştür (Uzuntarla ve Ceyhan, 2020; Altay ve Aydın, 2015); bununla birlikte olumsuz tutumlar belirleyen çalışmalar da mevcuttur (Köse, Ayhan, Taştan, İyigün, Hatipoğlu ve Açıkel, 2015). Yaşlılara yönelik tutumlarını etkileyen sebepler değişkenlik göstermekle birlikte; bu sebeplerden birisi alınan mesleki eğitimdir (King, Roberts ve Bowers, 2013; Pekçetin ve Günal, 2019).

Sağlık çalışanlarının tutumları, danışanlarıyla olan ilişkilerini büyük ölçüde etkiler (Altman, 1981). Diğer sağlık çalışanlarında olduğu gibi, bir ergoterapistin danışanlara karşı tutumu terapötik ilişkide önemli bir rol oynamaktadır. Ergoterapistlerle yapılan bir çalışmada (Benham, 1988), ergoterapistlerin engelli bireylere karşı olumlu tutumlara sahip oldukları ve olumsuz bir tutumun terapötik ilişkiyi olumsuz etkileyeceği bildirilmiştir. Ayrıca, bu çalışmaya katılan bireylerin çoğunluğu "olumlu tutumların ifade edilmesinin öğrenci seçiminde bir kriter olması gerektiği" konusunda hemfikirdir.

Öğrencilerin özellikle yaşlı bireyler ve engelli bireylerle ilgili tutumlarını etkilemek, ergoterapi müfredatının belirtilen bir hedefidir (AOTA, 1983). Mevcut çalışmanın sonuçları da ergoterapi lisans eğitiminin yaşlı bireylere karşı olumlu tutumu ve öğrencilerin özgeciliği üzerine olumlu etkisi olduğunu göstermektedir. Ergoterapi eğitiminin öğrencilerin engelli bireylerle ilgili tutumu üzerindeki etkisini inceleyen bir çalışmada (Estes, Deyer, Hansen ve Russell, 1991); giriş seviyesindeki ergoterapi öğrencilerinin engelli bireylere karşı nispeten olumlu tutumlara sahip olduğunu belirlenmiştir. Çalışma ayrıca danışanla hedefler belirlenirken ve danışana sağlanan hizmette iyimserlik, esneklik ve yaratıcılık gibi özelliklerin kullanılmasına dikkat çekilmiştir. Ülkemizde Ergoterapi lisans eğitimi dört yıldan oluşmakta ve 1. sınıftan itibaren tüm bireylere karşı adalet, empati, farklılıklara karşı hoşgörü, yardımseverlik, tüm bireylerin yaşamları boyunca en iyi düzeyde yaşam kalitesi ve iyilik haline sahip olma hakkı, bireylerin özellikle güçlü yönlerinin geliştirilmesi ve okupasyonlarla bağımsızlığın geliştirilmesi gibi kavramlar farklı derslerde ele alınmaktadır. Mevcut çalışmanın sonuçları ergoterapi eğitiminin öğrencilerin yaşlı bireylere karşı tutum ve düşüncelerine olumlu yönde etki ettiğini göstermektedir.

Çalışmada öğrencilerin özgecilik düzeyinde de artış olmuştur. Pickett (1962), birinci sınıfta kız öğrenciler üzerinde yaptığı çalışmada, ergoterapinin en güçlü iki yönünün "doğrudan insanlarla çalışmak ve engelli bireylere yardım etmek" olduğunu belirtmiştir. Holmstrom (1975), terapistlerin (ergoterapist, fizyoterapist ve dil ve konuşma terapisti) "güçlü bir şekilde insanlarla çalışmaya yöneldiklerini, özgecil hedeflere ve değerlere sahip olduklarını ve kişilerarası becerilerine son derece güvendiklerini" bulmuştur. Yapılan bir başka çalışmada ise (Özgöl, 2019); özgeciliğin yaşlılara yönelik tutumun anlamlı bir yordayıcısı olduğu belirlenmiştir. Mevcut çalışmanın bulguları da literatürü destekler niteliktedir (Pekçetin ve Günal, 2019).

Literatürde özellikle sağlık problemi olmayan yaşlı bireylerle erken eğitim deneyimleri de dâhil olmak üzere nesiller arası deneyimlerin yaşlı bireyler hakkında olumlu tutumları teşvik ettiği bulunmuştur 
(Bousfield ve Hutchison, 2010; Eymar ve Douglas, 2012). Yaşı ı bireylere karşı olumsuz tutumlarla mücadele etmek ve öğrencilerin yaşı bireylerle çalışmaya ve bu konuya olan ilgilerini artırmak için disiplinler arası eğitim stratejileri (örn. gerontoloji eğitimi kursları; yaşlı yetişkinlerle klinik ve hizmet deneyimleri ve yaşlı yetişkinlerle, özellikle sağıklı yaşılarla olumlu temasın sağlanması) önemlidir. Ergoterapide yaşı bireylerle ilgili eğitimin yaşlı bireylerle çalışma istekliliğine ve ilgisine katkıda bulunan bir faktör olarak rolü vurgulanmış ve öğrencilerin gelecekteki iş gücü intiyaçlarını ele almak için toplumsal alandaki uygulamalar ortamlarındaki bilgi ve deneyimlerini artırma intiyacı ortaya koyulmuştur (Horowitz, Tagliarino ve Look, 2014).

$\mathrm{Bu}$ çalışma; ergoterapi lisans eğitminin öğrencilerin yaşlı bireylere karşı olumlu tutumunu ve özgecilik düzeylerini arttırdığına dair kanıtlar sağlamaktadır. Mevcut çalışmanın salgın dolayısıyla çevrimiçi eğitimin sürdüğü bir dönemde gerçekleşmiş olması da elde edilen sonuçlar açısından ayrıca önemlidir. Covid-19 pandemisi nedeni ile öğrencilerin mesleki uygulama yapma olanakları oldukça sınırlı bir hale gelmiştir. Bu durum, ergoterapi öğrencilerinin özellikle Covid-19 açısından en riskli grup olarak görülen yaşı bireylerle olan temasının azalmasına neden olmuştur. Tüm bu limitasyonlara rağmen; çalışmanın sonuçları; çevrimiçi ergoterapi lisans eğitiminin olumlu etkilerine dikkat çekmektedir. Yaşlanan nüfus artışı göz önüne alındığında; ergoterapi lisans müfredatı öğrenciler için yaşlanma ve yaşılıkla ilgili daha fazla içeriği kapsayabilir.

Çalışmanın tek bir üniversitede yapılmış olması, sonuçların genellenebilirliği açısından bir limitasyon olarak düşünülebilir. Bununla birlikte; çalışmanın bu konuda ve bu kapsamda yapılmış ilk çalışma olması çalışmanın güçlü yönüdür. İlerideki çalışmalarda mezuniyet sonrası ergoterapistlerin çalışma alanları, bu alanları seçim nedenleri ve mezuniyet sonrası yaşı bireylere karşı tutumları ve özgecilik düzeylerinin incelenmesi önemlidir.

\section{Araştırmacıların Katkı Oranı}

Özgü INAL: Çalışmanın tasarımı, literatür taraması, materyal ve metod, verilerin analizi, makalenin yazımı.

Hülya YÜCEL: Çalışmanın tasarımı, literatür taraması, materyal ve metod, verilerin analizi, makalenin yazımı.

\section{Çıkar Çatışması Beyanı}

Yazarlar arasında çıkar çatışması bulunmamaktadır.

\section{Destek/Teşekkür}

Çalışma için hiçbir kurum ya da kişiden finansal destek alınmamıştır. Çalışmaya katılmayı gönüllü olarak kabul eden tüm katıımcılara yazarlar teşekkür eder.

\section{Kaynaklar}

Administration on Aging. (2003). Statistics On The Aging Population. US Department of Health and Human Services Rockville, MD.

Akbaba, S. (1994). Grupla Psikolojik Danışmanın Sosyal Psikolojik Bir Kavram Olan Özgecilik Üzerindeki Etkisi (Yayınlanmamış Doktora Tezi). Atatürk Üniversitesi Sosyal Bilimler Enstitüsü, Erzurum.

Altay, B., \& Aydın, T. (2015). Hemşirelik öğrencilerinin yaşlı ayrımcılığına ilişkin tutumlarının değerlendirilmesi. Koç Üniversitesi Hemşirelikte Eğitim ve Araştırma Dergisi (HEAD), 12(1), 11-18. https://doi.org/10.5222/HEAD.2015.011

Altman, B. M. (1981). Studies of attitudes toward the handicapped: The need for a new direction. Social Problems, 28(3), 321-337. https://doi.org/10.2307/800306

American Occupational Therapy Association. (2008). Occupational therapy practice freamework: Domain \& Process 2nd edition. Am J Occup Ther, 62, 625-683.

American Occupational Therapy Association. (1983). Essentials of an accredited educational program for the occupational therapist. Am J Occup Ther, 37(12), 817823. https://doi.org/10.5014/ajot.37.12.817

Benham, P. K. (1988). Attitudes of occupational therapy personnel toward persons with disabilities. Am J Occup Ther, $42(5)$,

305-311.. https://doi.org/10.5014/ajot.42.5.305

Bousfield, C., \& Hutchison, P. (2010). Contact, anxiety, and young people's attitudes and behavioral intentions towards the elderly. Educ Gerontol, 36(6), 451-466. https://doi.org/10.1080/03601270903324362

New York State Office for the Aging 2011-2015. (Retrieved from the Web October 14, 2021) http://www.op.nysed.gov/surveys/mhpsw/sofa-att1.pdf

Brown, C. A., Kother, D. J., \& Wielandt, T. M. (2011). A critical review of interventions addressing ageist attitudes in healthcare professional education. CJOT, 78(5), 282-293. https://doi.org/10.2182/cjot.2011.78.5.3

Duyan, V., \& Gelbal, S. (2013). Yaşlılara Yönelik Tutum Ölçeği'nin bir grup üniversite öğrencisi üzerinde Türkçeye uyarlama çalışması. Turkish Journal of Geriatrics/Türk Geriatri Dergisi, 16(2), 202-209.

Eisenberg, N., Fabes, R. A., \& Spinrad, T. L. (2006). Handbook of child psychology (Vol. 3, pp. 646-718). NJ: John Wiley \& Sons

Eshbaugh, E. M., Gross, P. E., \& Satrom, T. (2010). Predictors of self-reported likelihood of working with older adults. Educ Gerontol, 36(4), 312-329. https://doi.org/10.1080/03601270903058481

Estes, J. P., Deyer, C. A., Hansen, R. A., \& Russell, J. C. (1991). Influence of occupational therapy curricula on students' attitudes toward persons with disabilities. $\mathrm{Am} \mathrm{J}$ Occup Ther, 45(2), 156-159.

Eymard, A. S., \& Douglas, D. H. (2012). Ageism among health care providers and interventions to improve their attitudes 
toward older adults: An integrative review. J Gerontol Nurs, 38(5), 26-35. https://doi.org/10.3928/0098913420120307-09

Holmstrom, E. I. (1975). Promising prospects: students choosing therapy as a career. The American journal of occupational therapy: official publication of the American Occupational Therapy Association, 29(10), 608-614.

Horowitz, B. P., \& Vanner, E. (2010). Relationships among active engagement in life activities and quality of life for assisted-living residents. J Hous Elderly, 24(2), 130-150. https://doi.org/10.1080/02763891003757056

Horowitz, B. P., Savino, D., \& Krauss, A. (1999). Special feature: Ageism and implications for gerontic occupational therapy practice. Top Geriatr Rehabil, 15(2), 71-78.

Horowitz, B. P., Tagliarino, J., \& Look, K. (2014). Occupational therapy education, attitudes on aging, and occupational therapy students and therapists interest in gerontology practice. Phys Occup Ther Geriatr, 32(2), 136-151. https://doi.org/10.3109/02703181.2014.905898

King, B. J., Roberts, T. J., \& Bowers, B. J. (2013). Nursing student attitudes toward and preferences for working with older adults. Gerontol Geriatr Educ, 34(3), 272-291. https://doi.org/10.1080/02701960.2012.718012

Klein, J., \& Liu, L. (2010). Ageism in current practice: Experiences of occupational therapists. Phys Occup Ther Geriatr, 28(4), 334-347. https://doi.org/10.3109/02703181.2010.532904

Köse, G., Ayhan, H., Taştan, S., İyigün, E., Hatipoğlu, S., \& Açıkel, C. H. (2015). Determination of the attitudes of students from different department in the field of health on the discrimination against the elders. Gülhane Tip Dergisi, 57(2), 145.

Kogan, N. (1961). Attitudes toward old people: The development of a scale and an examination of correlates. J Abnorm Soc Psychol, 62(1), 44.

London, P., \& Bower, R. K. (1968). Altruism, extraversion, and mental illness. Soc Psychol, 76(1), 19-30.

Maiden, R. J., Horowitz, B. P., \& Howe, J. L. (2010). Workforce training and education gaps in gerontology and geriatrics: What we found in New York State. Gerontol Geriatr Educ, 31(4), 328-348. https://doi.org/10.1080/02701960.2010.532749

Özgöl, M. (2019). Yaşılara yönelik tutumların açıklanmasında özgecilik ve kişilik özelliklerinin rolü: karşılaştırmalı bir çalışma (Yükseklisans tezi). Trabzon Üniversitesi Lisansüstü Eğitim Enstitüsü, Trabzon.

Pekçetin, S., \& Günal, A. (2019). Sağlık bilimlerinin iki farklı bölümündeki öğrencilerin özgecilik düzeyinin incelenmesi. Ergoterapi ve Rehabilitasyon Dergisi, 7(1), 11-16.

Pickett, B. J. (1962). Factors influencing choice of occupational therapy as a career. Implications for recruitment of students. The American journal of occupational therapy: official publication of the American Occupational Therapy Association, 16, 84-88.

Powell, J. M., Kanny, E. M., \& Ciol, M. A. (2008). State of the occupational therapy workforce: results of a national study. Am J Occup Ther, 62(1), 97-105. https://doi.org/10.5014/ajot.62.1.97
Rozier, C. K., Gilkeson, G. E., \& Hamilton, B. L. (1992). Why students choose occupational therapy as a career. $A m \mathrm{~J}$ Occup Ther, 46(7), 626-632.

Taylor, S. E., Peplau, L. A., \& Sears, D. O. (2010). Sosyal Psikoloji (A. Dönmez, Çev.) TDK, Türk Dil Kurumu Yayınları, (2. Baskı). Ankara: İmge Kitabevi Yayıncılık.

Türkiye İstatistik Kurumu. İstatistiklerle Yaşılar, 2018. (Retrieved from the Web October 14, 2021). https://hsgm.saglik.gov.tr/depo/birimler/kronik-hastaliklarengelli-

db/hastaliklar/Yasli_Sagligi/raporlar_istatistikler/TUIK_Ya sli_Istatistik_2018.pdf

Uzuntarla, Y., \& Ceyhan, S. (2020). Ageism and altruism among students in the department of health technician training. J Clin Med Kaz, 4(58), 67-72. https://doi.org/10.23950/1812-2892-JCMK-00799

Whalley Hammell, K. R. (2015). Client-centred occupational therapy: The importance of critical perspectives. Scand $J$ Occup Ther, 22(4), 237-243.

WHO. Global strategy and action plan on ageing and health (2016-2020). (Retrieved from the Web April 4, 2021). https://www.who.int/ageing/GSAP-Summary-EN.pdf

WFOT, Entry-Level Competencies for Occupational Therapists. Retrieved from the Web April 4, 2021). https://wfot.org/resources/entry-level-competencies-foroccupational-therapists

Yazıcı, S. O., Kalayci, I., Kaya, E., \& Tekin, A. (2015). Attitudes of students in elderly care program towards ageism. Elderly Issues Research Journal, 2, 77-87. 